\title{
They're Monstrous! Teaching Flashed Face Distortion To Improve Speaking Apprehension
}

Kristen L. Majocha, University of Pittsburgh at Johnstown, USA

John W. Mullennix, University of Pittsburgh at Johnstown, USA

\begin{abstract}
Researchers have long established that people who believe they are attractive have higher self-esteem (Aronson \& Linder, 1965). Recent studies show that students with higher self-esteem have less speaking apprehension (Elfering \& Grebner, 2012). Teachers in higher education can help students rethink their attractiveness in an attempt to help boost their self-esteem through an in-class activity that demonstrates Flashed Face Distortion Effect. This improved self-appraisal can reduce speaking apprehension in any class that includes a public presentation element. This interpretive qualitative research presents a novel single-class activity that can be useful in any course that includes a public presentation element. The objective of the activity is to lower student speaking apprehension when they publically present.
\end{abstract}

Keywords: Flashed Face Distortion; Nonverbal Attractiveness; Public Speaking; Speaking Apprehension; SelfEsteem

\section{INTRODUCTION}

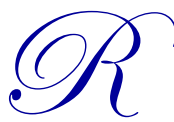

esearchers have established that people who believe they are attractive have higher self-esteem (Aronson \& Linder, 1965; Franzoi, 2017). Recent studies show that students with higher self-esteem have less speaking apprehension (Elfering \& Grebner, 2012). Furthermore, speakers with higher selfesteem are more persuasive (Carli, LaFleur, \& Loeber, 1995). Self-esteem is an integral part of communication, with low self-esteem causing an unwillingness to communicate (Pearson, Child, DeGreeff, Semiak, \& Burnett, 2011) and high self-esteem causing objective appraisals (Sparrow, 2005). Although the higher education teacher's role is to educate, students expect us to coach them on character development, relying on us for a sort of unconditional love (Arthur, 2011). This conflict (Fritz \& Omdahl, 2006) is resolved when students are taught to rethink their attractiveness.

Attractiveness is psychologically based. In this paper, we discuss how a recent perceptual phenomenon called Flashed Face Distortion Effect (Tangen, Murphy, \& Thompson, 2011) can help teach students how to view their body shape, facial features, and artifacts more positively. This improved view of self can boost self-esteem and allow students to more effectively persuade, thus lowering speaking apprehension. This interpretive qualitative research paper presents a novel single-class activity that is useful in any course that includes a public presentation element. The objective of the activity is to lower student speaking apprehension when they publically present.

\section{FLASHED FACE DISTORTION EFFECT}

Human faces differ, with eyes, noses, and mouths varying by size, shape, and protuberance (Leder \& Carbon, 2006). The distance between features varies from person to person as well (Leder \& Carbon, 2006). Perception of faces is important. According to Webster, Kaping, Mizokami, and Duhamel (2004), "Face perception is fundamentally important for judging the characteristics of individuals, such as identification of their gender, age, ethnicity or expression" (p. 557). In other words, when a perceptual alteration of a person's face occurs, judgments about that person can shift significantly. 
One example of distorted face perception is Flashed Face Distortion Effect (FFDE). A sequence of pairs of digitized faces is rapidly presented. The viewer is instructed to gaze on a midpoint between the two simultaneously presented faces (Bagaini \& Hole, 2017; Tangen et al., 2011). Viewers describe the resulting faces as highly deformed and grotesque. As described by Tangen et al. (2011), "Each face appeared as a caricature of itself. If a person had a large jaw, it looked particularly large, almost ogre-like. If a person had a slender nose, then it looked remarkably thin," (p. 628). Tangen et al. (2011), suggest that relative encoding of the two simultaneously presented faces creates this illusion. The effect depends on precise eye-alignment between the faces and a specific, steady presentation rate of four to five faces per second. If either of these conditions changes, the FFDE illusion disappears (Leder \& Carbon, 2006).

Tangen et al. (2011) noted that the FFDE illusion might be related to facial adaptation. Distorted perceptions of faces due to adaptation are well-known phenomena (e.g., see Hills, Holland, \& Lewis, 2010). These distortions are facial distortion aftereffects (Rhodes, 2017; Webster \& MacLin, 1999). For example, viewing a compressed face causes other faces to appear expanded (Rhodes, Jeffery, Watson, Clifford, \& Nakayama, 2003; Rhodes et al., 2004). Viewing a face with eyes artificially placed high causes other faces to appear to have lower eyes (Carbon \& Leder, 2006). Viewing a face with eyes gazing in one direction causes other faces to appear to gaze in the opposite direction (Jenkins, Beaver, \& Calder, 2006; Schweinberger, Kloth, \& Jenkins, 2007). Aftereffects have also been observed for attributes such as emotional expression (Benton et al., 2007; Hsu \& Young, 2004), identity (Hills, Elward, \& Lewis, 2008; Leopold, O’Toole, Vetter, \& Blanz, 2001), gender (Webster et al., 2004), and ethnicity (Jaquet, Rhodes, \& Hayward, 2007; Jaquet, Rhodes, \& Hayward, 2008; Little, DeBruine, Jones, \& Waitt, 2008; Rhodes, Watson, Jeffery, \& Clifford, 2010; Webster et al., 2004).

Because high self-esteem is such an integral part of a successful public presentation, teachers should address how perceptions of attractiveness relate to self-esteem. But improving self-esteem is generally outside the purview of most higher education classroom curriculums, thus creating a gap between student experiences and pedagogical methods for improving speaking apprehension. This interdisciplinary examination of communication studies and psychology will reveal how we can help students rethink their attractiveness to boost their self-image, lower their speaking apprehension, and improve their speaking effectiveness via an in-class FFDE activity.

This activity is most useful at the beginning of the term when students are feeling the most speaking apprehension and either when discussing stage fright or non-verbal behavior. Before conducting the activity, the instructor should connect nonverbal behavior/facial attractiveness (real or perceived) to self-confidence. Students should also understand the positive connection between improved self-confidence and diminished speaking apprehension. Once these connections are made, the instructor can discuss how attractiveness is relative and how even beautiful faces can appear unattractive and "monstrous" in some circumstances. The FFDE video is an example of this kind of relativity and reinforces the links between nonverbal behavior and perception. Supplemental materials are available at http://www.perceptionweb.com/misc.cgi?id=p6968 as well as http://petapixel.com/2012/05/22/flashed-facedistortion-effect-makes-ordinary-portraits-look-hideous/. A keyword search on YouTube for "flashed face distortion" will yield many suitable clips for this activity.

The videos demonstrate how attractiveness is relative and easily manipulated. Students will clearly see the link between manipulating nonverbal communication and improving attractiveness. Students should then understand how improving their nonverbal behavior can improve their self-confidence and in turn lessen their speaking apprehension. To fully understand the impact of the activity, the reader must view the FFDE video. The implications will be immediately understood.

\section{DISCUSSION}

After watching the FFDE videos, students overwhelmingly report lowered speaking apprehension and heightened awareness of the importance of nonverbal behavior when presenting. One student remarked, "You may be 'hot' to someone and 'not' to another. I can see how the way I feel about myself affects my stage fright." Other students said, "The video proved that someone you think is attractive might not be attractive to someone else. This lesson helps us speak better because our friends probably think we are more attractive than we think we are. Because celebrities do not look perfect all the time, it's ok if we do not look perfect all the time." This kind of reversal of perspective is 
highly valuable. As one student put it, "Self-esteem strongly affects how you feel about presenting." After the FFDE activity, students reported that it was obvious how subjective attractiveness was. This activity shows that students who lack self-esteem can watch the materials and, as a result, positively change their views about themselves and in turn lower their speaking apprehension.

\section{IMPLICATIONS}

Self-evaluation, one of the basic elements of presentation feedback, is affected by facial attractiveness. Studies show that people feel more attractive when they compare themselves to others whom they believe are less attractive than themselves. This phenomenon is called the contrast effect (Oikawa, et al., 2012; Tsukomoto \& Ohara, 2017). As a teacher, discussing the attractiveness of a student, especially in front of other students, is highly unethical and subjective. The FFDE activity offers a viable objective pedagogical method for improving the interpretation of attractiveness.

\section{LIMITATIONS}

The limitations to this activity include the difficulty in drawing a cause-and-effect relationship between the viewing of the materials and lowered speaking apprehension. Simply telling students the point of the activity may induce an observer effect, causing students to change their behavior before viewing the video. Another limitation may be that the reported lowering of speaking apprehension may be temporary. Variations of this activity could include showing celebrity pictures with and without makeup to demonstrate the subjective nature of attractiveness.

\section{CONCLUSION}

This novel single-class activity has been shown to effectively, albeit anecdotally, lower student speaking apprehension. Future studies could include pre and post-test surveys that quantitatively measure how levels of speaking apprehension change after students participate in watching the FFDE video.

\section{AUTHOR BIOGRAPHIES}

Kristen. L. Majocha, PhD has published several pedagogical works, most recently "Shades of Grey: An Interdisciplinary Approach to a Constructive Understanding of Diversity in the Communication Classroom," coauthored with John W. Mullennix, PhD, Qualitative Research Reports in Communication, 16.1, 2015. She has taught communication courses for 13 years, including speaking and listening courses for international students. She recently assumed the roles of Director of International Program Support and Services and Interim Assistant to the Vice President of Academic Affairs at Pitt-Johnstown. Her training includes the Pitt provost's workshop on diversity and NAFSA attendance.

Dr. John Mullennix is a Professor of Psychology at the University of Pittsburgh at Johnstown. He has published numerous research articles and several co-edited volumes in the areas of perception, memory, psycholinguistics, and experimental aesthetics. He also co-edited a book on practical techniques for addressing diversity issues in the college classroom. Dr. Mullennix has received awards for teaching excellence at Wayne State University and the University of Pittsburgh at Johnstown.

\section{REFERENCES}

Aronson, E., \& Linder, D. (1965). Gain and loss of esteem as determinants of interpersonal attractiveness. Journal of Experimental Social Psychology, 1, 156-171.

Arthur, J. (2011). Personal character of tomorrow's citizens: Student expectations of their teachers. International Journal of Educational Research, 50(3), 184-189.

Bagaini, A. \& Hole, G. (2017). Effect of vertical stretching on the extraction of mean identity from faces. Perception, 46(9), 1048-1061.

Benton, C. P., Etchells, P. J., Porter, G., Clark, A. P., Penton-Voak, I. S., \& Nikolov, S. G. (2007). Turning the other cheek: The viewpoint dependence of facial expression after-effects. Proceedings of the Royal Society B: Biological Sciences, 274, 2131-2137. 
Carli, L., LaFleur, S., \& Loeber, C. (1995). Nonverbal behavior, gender, and influence. Journal of Personality and Social Psychology, 68(6), 1030-1041.

Carbon, C. C., \& Leder, H. (2006). Last but not least. Perception, 35, 411-414.

Elfering, A., \& Grebner, S. (2012). Getting used to academic public speaking: Global self-esteem predicts habituation in blood pressure response to repeated thesis presentations. Applied Psychophysiology and Biofeedback, 37(2), 109-120.

Franzoi, S. (2017). Body esteem scale. Editors Virgil Zeigler-Hill and Todd K. Shackelford. Encyclopedia of personality and individual differences. New York, NY: Springer International Publishing.

Fritz, J. M. H., \& Omdahl, B. L. (2006). Problematic relationships in the workplace. New York, NY: Peter Lang.

Hills, P. J., Elward, R. L., \& Lewis, M. B. (2008). Face identity after effects are mediated and moderated by visualization abilities. Perception, 37, 1241-1257.

Hills, P. J., Holland, A. M., \& Lewis, M. B. (2010). Aftereffects for face attributes with different natural variability: Children are more adaptable than adolescents. Cognitive Development, 25, 278-289.

Hsu, S. M., \& Young, A. W. (2004). Adaptation effects in facial expression recognition. Visual Cognition, 11, 871-899.

Jaquet, E., Rhodes, G., \& Hayward, W. G. (2007). Opposite aftereffects for Chinese and Caucasian faces are selective for category information and not just physical face differences. The Quarterly Journal of Experimental Psychology, $60(11), 1457-1467$.

Jaquet, E., Rhodes, G., \& Hayward, W. G. (2008). Race-contingent aftereffects suggest distinct perceptual norms for different race faces. Visual Cognition, 16(6), 734-753.

Jenkins, R., Beaver, J. D., \& Calder, A. J. (2006). I thought you were looking at me. Psychological Science, 17(6), $506-513$.

Leder, H., \& Carbon, C. C. (2006). Face-specific configural processing of relational information. British Journal of Psychology, 97, 19-29.

Little, A. C., DeBruine, L. M., Jones, B. C., \& Waitt, C. (2008). Category contingent aftereffects for faces of different races, ages, and species. Cognition, 106, 1537-1547.

Leopold, D. A., O’Toole, A. J., Vetter, T., \& Blanz, V. (2001). Prototype-referenced shape encoding revealed by high-level aftereffects. Nature Neuroscience, 4, 89-94.

Oikawa, H, Sugiura, M., Sekiguchi, A., Tsukiura, T., Miyauchi, C., Hashimoto, T., ...\& Kawashima, R. (2012). Self-face evaluation and self-esteem in young females: An fMRI study using contrast effect. NeuroImage, 59(4), 3668-3676.

Pearson, J., Child, J., DeGreeff, B., Semiak, J., \& Burnett, A. (2011). The influence of biological sex, self-esteem, and communication apprehension on unwillingness to communicate. Atlantic Journal of Communication, 19(4), $216-227$.

Rhodes, G. (2017). Adaptive Coding and Face Recognition. Current Directions in Psychological Science, 26(3), $218-224$.

Rhodes, G., Jeffery, L., Watson, T. L., Clifford, C. W. G., \& Nakayama, K. (2003). Fitting the mind to the world: Face adaptation and attractiveness after effects. Psychological Science, 14(6), 558-566.

Rhodes, G., Jeffery, L., Watson, T. L., Jaquet, E., Winkler, C., \& Clifford, C. W. G. (2004). Orientation-contingent face aftereffects and implications for face-coding mechanisms. Current Biology, 14, 2119-2123.

Rhodes, G., Watson, T. L., Jeffery, L., \& Clifford, C. W. G. (2010). Perceptual adaptation helps us identify faces. Vision Research, 50, 963-968.

Schweinberger, S. R., Kloth, N., \& Jenkins, R. (2007). Are you looking at me? Neural correlates of gaze direction. Neuroreport, 18(7), 693-696.

Sparrow, J. (2005). Self-esteem and how it grows. Scholastic Parent and Child, 13(1), 60-63.

Tangen, J., Murphy, S., \& Thompson, M. (2011). Flashed face distortion effect: Grotesque faces from relative spaces. Perception, 40, 628-630.

Tsukamoto, M. \& Kohara, K. (2017). Using the implicit association test and choice to measure the within-trial contrast effect in human adults. The Psychological Record, 67, 507-518.

Webster, M. A., Kaping, D., Mizokami, Y., \& Duhamel, P. (2004). Adaptation to facial categories. Nature, 428, $557-561$.

Webster, M. A., \& MacLin, O. H. (1999). Figural aftereffects in the perception of faces. Psychonomic Bulletin \& Review, 6(4), 647-653. 